\title{
MAKNA KATA-KATA MUTIARA (QUOTES) BJ HABIBIE: TINJAUAN KESANTUNAN BERBAHASA
}

\author{
Prasetya Wulan Esther Wijaya \\ wulanesther@yahoo.com \\ Golda J. Tulung \\ gtulung@unsrat.ac.id \\ Mariam Pandean \\ mariampandean@unsrat.ac.id
}

\begin{abstract}
Abstrak.
This study aims to describe the meaning of BJ Habibie's Quotes based on linguistic politeness. Data sources were collected from BJ Habibie Quotes through online news. The research method that used in this research is descriptive qualitative method. Quotes of BJ Habibie in this study has a strong principle of linguistic politeness which includes; (1) formality scale, (2) hesitancy scale, and (3) equality scale, and as interpreted as affective meaning. The result of this study was obtained to a strong principle in every quotes that have a common understanding to the linguistic politeness principle that has been expressed by Robin Lakoff.
\end{abstract}

Keywords : linguistic politeness, quotes, Bj Habibie 


\section{PENDAHULUAN}

Chaer (1981:7) Ungkapan adalah satuan bahasa entah berupa kata, frasa maupun kalimat yang maknanya tidak dapat ditarik dari kaidah umum gramatikal yang berlaku dalam bahasa tersebut, atau tidak dapat diramalkan dari makna leksikal unsur-unsur yang membentuknya.

Makna adalah bagian yang tidak terpisahkan dari semantik dan selalu melekat dari apa saja yang kita tuturkan. Pengertian dari makna sendiri sangatlah beragam. Mansoer Pateda (2001:79) mengemukakan bahwa istilah makna merupakan kata-kata dan istilah yang membingungkan.Makna tersebut selalu menyatu pada tuturan kata maupun kalimat.

Baru-baru ini seiring kabar kematian BJ Habbie yang banyak menyita perhatian masyarakat Indonesia yang diliput di berbagaimedia baik di media masa baik koran maupun berita online, TV dan berbagai media sosial, seperti facebook, twiter, instagram, sehingga banyak para pengguna aktif media sosial yang membagikan kata-kata mutiara (Quotes) di akun media sosialnya yang sengaja

diambil dari berbagai lini media masa online yang menyajikan daftar kata-kata mutiara (Quotes) BJ Habibie sepeninggalnya sang bapak teknologi Indonesia itu.

Walaupun hanya sekedar kata-kata, tidak jarang setelah membacanya seseorang akan merenungkan makna dari kata mutiara (Quotes) yang kita baca tersebut. Sebagai contoh kata-kata mutiara yang sering menjadi inspirasi banyak pengguna adalah kata-kata mutiara dari BJ Habibie. Tidak sedikit pembaca yang termotivasi oleh kata-kata BJ Habibie, karena kata-kata BJ Habibie banyak membuat 
pembacanya merasa tersentuh hatinya oleh kebijaksanaan kata-kata mutiara yang ungkapkan oleh BJ Habibie.

Kata-kata BJ Habibie yang santun memiliki nilai rasa yang nikmat bagi pembacanya, landasan kata mutiara BJ Habibie adalah nasehat atau petuah tentang kehidupan secara puitis, cerdas, penuh kasih saying dan praktis daam realita kehidupan sehari-hari. Kata-kata yang digunakan oleh BJ Habibie selalu bisa memberikan kekuatan baru bagi para pembacanya. Keunikan kata serta permainan bahasa yang disusun oleh BJ Habibie menarik minat penulis untuk mengakaji kesantunan berbahasa yang digunakan oleh BJ Habibie.

Pengkajian ini dilakukan untuk mempermudah memahami kata-kata mutiara yang disampaikan oleh BJ Habibie, sekaligus agar nilai-nilai yang diungkapkan BJ Habibie kepada pembacanya dapat diterima dengan baik tanpa ada kendala dalam pemahaman makna yang diungkapkan sehingga memotivasi setiap individu yang membacanya

Pada penelitian ini akan sampai pada pembahasan kesantunan berbahasa. Menurut Robin Klakoff (dalam Kunjana, (2005: 70) terdapat tiga ketentuan untuk dapat dipenuhinya kesantunan di dalam kegiatan bertutur. Ketiga ketentuan itu yakni: (1) skala formalitas (formality scale), (2) skala ketidakjelasan (hesitancy scale), dan (3) 484 skala kesamaan atau kesekawanan (equality scale).

Berdasarkan latar belakang yang di atas, maka masalah dalam penilitin ini yaitu, Bagaimana Makna kata-kata mutiara (Quotes) BJ Habibie berdasarkan 
kesantunan berbahasa. Kemudian tujuan dalam penelitian ini untuk mendeskripsikan makna kata-kata mutiara (Quotes) BJ Habibie berdasarkan kesantunan berbahasa.

Beberapa penelitian terkait yang pernah dilakukan oleh (1) Ningsi N, 2014. Analisis Makna Kata Mutiara Pada Acara Televisi Hitam Putih di Trans 7 Bulan Agustus 2011: Tinjauan Semantik. Skripsi. Tujuan dari penelitian ini adalah 1. Memaparkan bentuk kata-kata mutiara yang terdapat dalam acara televisi Hitam Putih di Trans7 pada bulan Agustus 2011, 2. mendiskripsikan makna yang terdapat dalam kata mutira dalam acara televisi Hitam Putih di Trans7 bulan Agustus 2011. (2) Rahmawati H, Ikhwan M, Abbas A. 2018. Kekuatan Makna Ungkapan Dalam Novel-Novel Tere Liye: Kajia Semantik. Artikel. Penelitian ini bertujuan untuk menguraikan: 1. ekspresi bijak dalam bentuk bijaksana novel-novel Tere Liye "Rindu" dan "Pukat", 2. makna tersirat dalam ekspresi bijak, dan 3. kekuatan makna ekspresi bijak dalam percakapan, sehingga konten makna dapat ditemukan.

\section{METODOLOGI PENELITIAN}

Metode Penelitian ini menggunakan pendekatan destriptif, kualitatif dengan teknik analisis isi, pendekatan kualitatif menggunakan prosedur yang menghasilkan data deskriptif berupa data tertulis atau lisan dalam masyarakat bahasa (Djajasudarma, 2006:10). Teknik analisis data dilakukan dengan membahas secara mendalam data yang diperoleh dari data tertulis dalam berita laman online.

Teknik penelitian yang digunakan adalah teknik deskriptif kualitatif. Menurut Bagdan dan Taylor (lewat Moleong, 2002 : 31) penelitian kualitatif adalah penelitian 
yang menghasilkan data deskriptif, yaitu dari yang berupa kata-kata tertulis / lisan dari orang-orang atau perilaku yang diamati.

\section{HASIL PENELITIAN DAN PEMBAHASAN}

\section{Hasil Penelitian}

Berdasarkan penelitian yang telah dilakukan ditemukan 9 (Sembilan) data katakata mutiara (Quotes) BJ Habibie yang mngandung makna dan kesantunan berbahasa. Hasil analisis tersebut terdiri dari 3 data kata-kata mutira (Quotes) yang memiliki makna semantik berdasarkan kesantunan berbahasa berskala formalits (formality scale), 3 data kata-kata mutira (Quotes) yang memiliki makna semantik berdasarkan kesantunan berbahasa Skala (hesitancy scale), 3 data kata-kata mutira (Quotes) yang memiliki makna semantik berdasarkan kesantunan berbahasa, Skala Kesantunan kesekawanan (equality scale).

1. Skala Formalitas (Formality Scale)

a. "Salah satu kunci kebahagiaan adalah menggunakan uangmu untuk pengalaman, bukan untuk keinginan"

b. "Jadilah anak muda yang produktif, sehingga menjadi pribadi yang profesional dengan tidak melupakan dua hal, yaitu iman dan takwa." 
c. "Cinta sejati itu memandang kelemahan lalu diubah menjadi sebuah kelebihan untuk selalu mencintai."

Dari kata mutiara yang dikemukakan oleh BJ Habibie pada kata-kata mutiara yang dicontohkan di atas:

Bagian (a) di atas, tidak ada kata-kata yang memiliki unsur-unsur makna pemaksaan kepada pembacanya kata-kata yang disampaikan oleh BJ Habibie di atas memberikan nalar pada pembacanya untuk menggunakan sesuatu (dalam hal ini uang) untuk dipakai dan dimanfaatkan sebaik-baiknya sesuai kebutuhan dan memberi makna positif pada pembacanya secara sederhana namun efektif dengan bahasa yang ringan.

Bagian (b) Quotes BJ Habibie di atas memberikan makna positif agar selalu semangat dan memotivasi bagi insan muda untuk memacu diri dan kemampuan pribadi agar dapat berkarya sesuai minat masingmasing tanpa menggunakan bahasa yang menggurui, namun ia juga mengingatkan pembacanya untuk tidak melupakan hal yang terpenting dalam berkarya adalah prinsip hidup yang berlandaskan iman dan ketakwaan kita, karena itu adalah kunci dalam sebuah perjalanan hidup.

Bagian (c) Quotes BJ Habibie memiliki makna yang mendalam tentang tindakan seseorang untuk memaknai kekurangan itu bukan sebagai hal yang selalu negatif, karena cinta adalah cara untuk 
menyatukan perbedaan dan mengubahnya menjadi keindahan. Dengan begitu mampu untuk mempersatukan perbedaan menjadi satu kesatuan. Habibie dan Ainun. Dua-duanya memiliki kekurangan dan kelebihan, tapi ketika saling mencintai, keduanya saling melengkapi.

2. Skala ketidakjelasan (Hesitancy Scale)

a. "Hiduplah kamu seperti akan mati besok. Dan berbahagialah seperti kamu akan hidup selamanya"

b. "Kesetiaan berarti ketulusan untuk menyimpan satu hati di dalam hati, dan berjanji untuk tidak mengkhianati."

c. "Cinta tidak berupa tatapan satu sama lain, tetapi memandang ke luar bersama ke arah yang sama."

Bagian (a) Quotes BJ Habibie bermakna selama masa hidupmu jangan lah terlalu mensia - siakan waktu. Karena waktu sangatlah berharga. Jalani hidupmu dengan serius seakan-akan besok kamu akan mati. Namun terkait kebahagiaan, senantiasalah bahagia seperti kamu tidak pernah menemukan masalah barang satu kalipun

Selanjutnya Quotes BJ Habibie di bagian (b) bermakna bahwa kesetiaan adalah tentang menjaga hati. Juga sebuah komitmen untuk tidak melanggar apa yang sudah sama-sama disepakati dalam sebuah ikrar suci. 
Quotes BJ Habibie di bagian (c) mengandung makna tentang Cinta yang sejati tidak hanya melingkupi aku dan kamu saja, tetapi ada halhal mulia yang bisa dicapai bersama-sama. Menuju masa depan yang sama. Bermanfaat untuk orang lain bersama-sama.

\section{Skala Kesantunan kesekawanan (Equality Scale)}

a. "Masa lalu saya adalah milik saya. Masa lalu kamu adalah milik kamu. Tapi, masa depan adalah milik kita"

b. "Tak perlu seseorang yang sempurna. Cukup temukan orang yang selalu membuatmu bahagia. Dan membuatmu berarti lebih dari siapapun"

c. "Walaupun raga telah terpisahkan oleh kematian, namun cinta sejati tetap akan tersimpan secara abadi di relung hati.”

Bagian (a) dari Quotes BJ Habibie memiliki makna tentang waktu, perasan cinta dan tujuan kedepan sehingga cinta yang sejati tidak hanya melingkupi aku dan kamu saja, tetapi ada hal-hal mulia yang bisa dicapai bersama-sama. Menuju masa depan yang sama. Bermanfaat untuk orang lain bersama-sama.

Bagian (b) dari Quotes BJ Habibie mempunyai makna tentang perasaan, cinta dan sikap seseorang, BJ Habibie mengutarakan bahwa manusia tak ada yang sempurna, karena kesempurnaan hanyalah milik Tuhan semata. Konsep kesempurnaan yang dimiliki manusia 
hanyalah: hari ini harus lebih baik daripada kemarin. Juga, menemukan seseorang yang bisa melengkapi kekurangan-kekurangan kita; itulah kesempurnaan di sisi manusia.

Bagian (c) dari Quotes BJ Habibie memiliki makna diantaranya perasaan, cinta dan kenangan. Sebenarnya BJ Habibie mengutarakan kata-kata indah untuk tersebut kepada mendiang istrinya Ainun. Begitu terasa energi cinta mereka menembus ruang dan waktu. Memang, kematian hanyalah perpisahan sementara untuk kehidupan selanjutnya dan pertemuan berikutnya dengan kekasih sejati.

\section{Pembahasan}

Pada penelitian ini telah mengunakan teori dari Menurut Robin Klakoff untuk menganalisis dan mengklasifikasikan kesantunan berbahasa dan makna semntik menggunakan terdapat tiga ketentuan untuk dapat dipenuhinya kesantunan di dalam kegiatan bertutur. Ketiga ketentuan itu yakni: (1) skala formalitas (formality scale), (2) skala ketidakjelasan (hesitancy scale), dan (3) 484 skala kesamaan atau kesekawanan (equality scale). Uraian mengenai masing-masing skala kesantunan tersebut sebagai berikut.

a. Skala Formalitas (formality scale)

Supaya para peserta tutur dapat merasa nyaman dan tidak bosan dalam kegiatan bertutur, tuturan yang digunakan tidak boleh bernada memaksa dan 
tidak boleh berkesan angkuh. Dalam kegiatan ini peserta tutur harus menjaga keformalitasan dan menjaga jarak yang sewajarnya atau secara realistis.

b. Skala ketidakjelasan (hesitancy scale)

Skala ketidakjelasan seringkali disebut dengan skala pilihan (optionally scale). Skala ini menunjukkan bahwa agar penutur dan mitra tutur dapat saling merasa nyaman dan tidak bosan dalam bertutur, pilihan-pilihan dalam bertutur harus diberikan oleh kedua belah pihak. Dalam hal ini keduannya tidak boleh bersikap tegang dan kaku, karena akan dianggap tidak santun. Dalam skala ini strategi yang digunakan dalam bertutur menggunakan kaidah penghormatan atau memberi pilihan kepada mitra tutur agar melakukan sesuatu.

c. Skala kesamaan atau kesekawanan (equality scale)

Agar dalam bertutur menunjukkan sifat santun, orang haruslah bersikap ramah, akrab, dan selalu mempertahankan persahabatan. Agar hal itu tercapai, penutur harus menganggap mitra tutur sebagai sahabat. Jika hal itu dilakukan, hadirlah rasa kekawanan dan kesejajaran yang akan tercapai kesantunan dalam bertutur. Dalam hal ini, strategi persahabatan harus dimunculkan dalam bertutur.

\section{Makna semantik}

Berdasarkan hasil penelitian, teori yang digunakan untuk menganalisis makna dari kata-kata mutiara (Quotes) BJ Habibie yaitu teori dari Geoffrey Leech (1976), 
dan dianalisis hanya pada makna afektif. Menurut Leech makna afektif, yaitu istilah yang dipakai untuk jenis makna di atas, sering kali secara eksplisit diwujudkan dengan kandungan konseptual atau konotatif dari kata-kata yang dipergunakan. Makna afektif sebagian besar termasuk kategori parasit dalam arti bahwa untuk mengungkapkan emosi, kita menggunakan perantara kategori makna lain; konseptual, konotatif atau stilistik.

\section{SIMPULAN DAN SARAN}

Dari beberapa makna yang telah dikupas melalui kajian kesantunan berbahasa Robin Lakoff dari kata-kata BJ Habibie, dapat disimpulkan bahwa setiap kata-kata yang diungkapkan BJ Habibie berisi tentang semangat hidup, cara menyikapi sesuatu dan pantang menyerah, kalimat-kalimat ini diujarkan dengan bahasa yang santai dan mudah dicerna. Namun setiap kata-kata yang diujarkan oleh BJ Habibie walaupun sederhana selalu memiliki nilai yang mendalam bagi para pembacanya.

Saran yang akan disampaikan kepada para pembaca, hendaknya ketika kita menuturkan sesuatu, tidak perlu mengibaratkan sesuatu yang muluk-muluk, dan dengan bahasa yang berbelit-belit, cukup dengan ungkapan yang sederhana tapi mengena di hati pembacanya. 


\section{Daftar Pustaka}

Cummings, Louise. 2007. Pragmatik Sebuah Perspektif Multidisipliner. Yogyakarta: Pustaka Pelajar .

Rahardi, Kunjana. 2003. Berkenalan Dengan Ilmu Bahasa Pragmatik. Malang: Dioma.

Rahardi, Kunjana. 2005. Pragmatik Kesantunan Imperatif Bahasa Indonesia. Jakarta: Erlangga

Rohmadi, M. 2011. Analisis Wacana Pragmatik. Surakarta: Yuma Pustaka.

Rohmadi, Muhammad. 2004. Pragmatik: Teori dan Analisis. Yogyakarta: Lingkar Media

Sarwiji Suwandi. 2011. Semantik Pengantar Kajian Makna. Yogyakarta: Media Perkasa.

Sudaryat, Yayat. 2008. Makna dalam Wacana Prinsip-Prinsip Semantik dan Pragmatik. Bandung:

Yrama Widya Sulistyo, Edy Tri. 2013. Pragmatik Suatu Kajian Awal. Surakarta:UNS

Press. Yule, G. (1996). Pragmatik. Yogyakarta: Pustaka Pelajar. 